\title{
Jogos de gênero: \\ o recreio numa escola de ensino fundamental ${ }^{*}$
}

\author{
Tânia Mara Cruz ${ }^{* *}$ \\ Marilia Pinto de Carvalho***
}

\begin{abstract}
Resumo
Baseado em pesquisa etnográfica realizada em 2001 numa escola pública de São Paulo, este artigo trata das relações de gênero entre crianças de 7 a 10 anos, especialmente durante os recreios. Focamos as interações conflituosas entre os sexos, buscando revelar as múltiplas nuances dos jogos de poder que ações aparentemente similares escondiam. Ao articular o conceito de conflito a significados simultaneamente lúdicos e de agressividade, passamos a compreendê-lo como "jogos de gênero", um dos modos possíveis de sociabilidade nas relações entre meninos $e$ meninas.
\end{abstract}

Palavras-chave: Recreio Escolar, Brincadeiras, Relações de Gênero, Conflito.

\footnotetext{
" Recebido para publicação em fevereiro de 2006, aprovado em março de 2006.

** Assistente Pedagógica da UnA Tecnológica e Professora em Educação a Distância da Universidade do Sul de Santa Catarina (UNISUL). taniamara.cruz@gmail.com

**** Professora Doutora da Faculdade de Educação da Universidade de São Paulo e pesquisadora do CNPq. mariliac@usp.br
} 
Jogos de gênero

Gender Play:

Break Time in a Primary School

\begin{abstract}
Based upon an ethnographic study of children's break time in a primary school in São Paulo, this article analyses the gender relations among children from 7 to 10 years old. We focus on the conflicting relationships between the sexes in an attempt to show the multiple forms of power play hidden behind apparently similar actions. By articulating the concept of conflict with simultaneous meanings of aggression and joking, we use the concept of "gender play" as one of the possible ways of sociability between boys and girls.
\end{abstract}

Key Words: Break Time, Play, Gender Relations, Conflict. 
Este artigo traz os resultados de uma pesquisa etnográfica realizada em 2001 e trata das relações de gênero entre crianças de 7 a 10 anos ( $1^{\text {a }}$ a $4^{\text {a }}$ séries) numa escola pública localizada na cidade de São Paulo. ${ }^{1}$ Diante da exigüidade da produção acadêmica existente sobre gênero $e$ infância, particularmente na faixa etária a que nos propúnhamos a trabalhar, nosso objetivo inicial era observar as relações de gênero entre crianças para, a partir daí, definirmos as problemáticas emergentes e selecionar, dentre elas, um objeto de estudo pertinente. A dificuldade de observar agrupamentos infantis no cotidiano da rua levou-nos ao recreio escolar, um espaço que, embora esteja determinado pelas relações institucionais em que está inserido, possui relativa autonomia do mundo adulto. Este estudo reflete, portanto, um determinado recorte da vivência das relações de gênero entre crianças em um contexto escolar.

Muitas possibilidades de estudo emergiram da análise do material de campo, mas desde o início, a questão dos conflitos entre as crianças continuamente permeava nossos questionamentos. Já em nossa chegada, a diretora da escola nos havia informado sobre a preocupação da equipe escolar com o que designavam como "violência entre as crianças", a qual havia gerado até mesmo uma proposta de reorganização do recreio com definição de novas funções aos inspetores $e$ inspetoras de alunos(as). A atribuição do termo "violência" às hostilidades entre as crianças foi um dos pontos que nos chamou a atenção: efetivamente, ao primeiro olhar, o recreio apresentava-se caótico. Se um maior número de meninos podia ser visto em brincadeiras que envolviam contato físico (em especial as "lutinhas"), havia também meninos e meninas participando de xingamentos, troca de tapas, correrias e pega-pegas.

Havia diferentes formas de interação durante o recreio, tanto em grupos intra-sexo quanto em grupos mistos, que

${ }^{1}$ CRUz, Tânia Mara. Meninas e meninos no recreio: gênero, sociabilidade e conflito. Tese de Doutorado em Sociologia da Educação/USP, 2004. 
Jogos de gênero

apresentavam variabilidades no tocante às brincadeiras $e$ ações, assim como nos tipos de conflito permitidos e no grau perceptível de harmonia ou conflito. ${ }^{2}$ A busca por uma compreensão mais nuançada destas diferentes formas de interação, em especial aquelas que se davam em grupos mistos, levou-nos a priorizar o conceito de conflito. Particularmente ao articular este conceito a possíveis significados lúdicos e de agressividade, utilizando os conceitos de "jogo" e "jogos de gênero", passamos a compreender o conflito como um dos modos possíveis de sociabilidade nas relações de gênero, o que nos permitiu avançar na compreensão das relações entre meninos e meninas naquela escola. Foi possível relativizar a aplicação do conceito de violência a quaisquer desses conflitos incorporando a dimensão lúdica destas interações. Neste artigo focaremos especialmente as interações conflituosas entre os sexos, buscando revelar as múltiplas nuances dos jogos de poder que ações aparentemente similares escondiam.

\section{O contexto da pesquisa}

Apesar de o recreio ter sido o locus principal da observação das interações infantis, houve também entrevistas $e$ acompanhamento em alguns momentos de sala de aula, nas disciplinas de educação artística e educação física, com as crianças de nove e dez anos ( $3^{\mathrm{a}} \mathrm{s}$ e $4^{\mathrm{a}} \mathrm{s}$ séries). ${ }^{3}$ Durante o recreio conversávamos com os inspetores de alunos $e$ ao final da pesquisa, também os entrevistamos.

A escola pesquisada, localizada na zona oeste da cidade de São Paulo, atendia a cerca de 670 alunos e possuía 40 professores. Nas séries iniciais havia duas turmas por série, com 30 alunos cada, perfazendo um total de 240 crianças. A equipe técnico-

\footnotetext{
2 ID., IB.

${ }^{3}$ Foram observadas cerca de 240 crianças no recreio ( $1^{\mathrm{a}}$ a $4^{\mathrm{a}}$ série) e realizadas 55 entrevistas dentro de um universo de 120 crianças ( $3^{\mathrm{a}}$ a $4^{\mathrm{a}}$ série).
} 
Tânia Cruz e Marília Carvalho

pedagógica era composta por duas orientadoras pedagógicas, uma atendendo da $1^{\mathrm{a}}$ à $4^{\mathrm{a}}$ série e outra da $5^{\mathrm{a}}$ em diante. Além da equipe administrativa e de um serviço de limpeza (terceirizado), a escola dispunha de quatro pessoas para exercer a função de inspeção de alunos e alunas, sendo que três deles (duas mulheres e um homem) eram responsáveis pelo acompanhamento das crianças de $1^{\mathrm{a}}$ a $4^{\mathrm{a}}$ séries.

Em cada turma havia uma proporção semelhante entre meninos e meninas, dos quais cerca de $60 \%$ eram negros (pretos ou pardos) e $40 \%$ não-negros. ${ }^{4} \mathrm{O}$ critério de composição do alunado agregava procedências sócio-culturais muito diversas. Eram crianças cujos pais e mães trabalhavam como funcionários públicos, professores de todos os níveis de ensino, profissionais liberais, trabalhadores domésticos, operários, motoristas de caminhão, funcionários do setor de comércio ou comerciantes, etc. As crianças residiam tanto em condomínios fechados como casas e apartamentos em áreas residenciais ou comerciais, ou ainda em moradias simples, de madeira, próximas à escola. ${ }^{5}$

O grande pátio escolar lembrava um parque, ainda que descuidado. Todo circundado por alambrados, exibia a grama por fazer, algumas cadeiras velhas resultantes da reforma de um anfiteatro, conjunto de elementos que disputavam nossa visão com jardins intercalados de terra batida ou áreas cimentadas. Aqui e ali muitas árvores frutíferas e algumas flores esparsas. Parte do pátio a céu aberto fazia fronteira com um rio e tinha demarcadas no chão as linhas de um campo de futebol de salão. Do lado

\footnotetext{
${ }^{4}$ De acordo com auto-classificação feita pelas crianças no bojo da pesquisa "Fracasso escolar: articulações entre gênero e cor/raça". Ver CARVALHO, Marilia. $\mathrm{O}$ fracasso escolar de meninos e meninas: articulações entre gênero e cor/raça. Cadernos Pagu (22), Núcleo de Estudos de Gênero -Pagu/Unicam, jan./jun. 2004, pp.247-290; e Quem são os meninos que fracassam na escola? Cadernos de Pesquisa, vol. 34, n 121, São Paulo, jan./abr. 2004, pp.11-40.

5 Informações obtidas em conversa com a diretora da escola e posteriormente corroboradas pelas crianças, professores(as) e inspetores(as) no decorrer da pesquisa.
} 
Jogos de gênero

oposto havia uma pequena quadra de vôlei, ambos sem redes. $\mathrm{Na}$ parte coberta havia uma amarelinha pintada no chão. Neste espaço havia algumas mesas e cadeiras para lanche que eram utilizadas pelas crianças, mas a maioria preferia lanchar no chão enquanto se esquivava das boladas vindas de todos os lados, resultantes dos inúmeros jogos de futebol simultâneos.

A cozinha da Associação de Pais ficava em um dos lados do pátio coberto e oferecia alimentação programada por nutricionista, tanto para pagantes (mensalistas) quanto para crianças cujos pais não pagavam a mensalidade e eram incluídas numa lista interna de "assistidos". Próxima às salas de aula havia uma lanchonete terceirizada, mais procurada pelas crianças da $5^{a}$ série, que compartilhavam dez dos 30 minutos de recreio das séries iniciais. Essas crianças maiores mantinham-se a uma distância relativa das menores.

Duas mudanças ocorreram no recreio logo no início da pesquisa: a deliberação da escola em fechar para reforma um playground existente na lateral do prédio e a utilização obrigatória de uniforme por todas as crianças. O fechamento da área de brinquedos impediu um processo que se iniciava de observação do uso diferenciado dos equipamentos por meninos e meninas. Já a obrigatoriedade do uniforme dificultou a percepção de possíveis diferenças sócio-econômicas manifestas no modo de vestir e suas articulações com as relações de gênero. Essa percepção foi também dificultada pelo fato do lanche da Associação de Pais ser distribuído indistintamente entre pagantes ou não $e$, dessa forma, não foi possível detectar a segmentação sócio-econômica como um fator de diferenciação interna entre as crianças, diferentemente das questões étnico-raciais ou de orientação sexual presentes na constituição das identidades infantis ali observadas. ${ }^{6}$ A diferenciação sócio-econômica existia, segundo as inspetoras, mas era mais sutil $e$ sua percepção $e$ análise provavelmente dependeriam de um tempo maior de pesquisa empírica.

6 Ver CRUZ, T. M. Meninas e meninos no recreio... Op. cit. 
O trabalho de campo iniciou-se com um mês de visitas semanais sem registros escritos, o que foi uma opção de imersão frente a ambiente tão vasto, diversificado e em constante alteração como era o pátio de recreio. Após este período, houve registros semanais, com exceção das férias do meio de ano. Ao todo foram 28 registros, que priorizaram as ações observadas, mas incluíram também conversas com as crianças sobre os fatos ali vivenciados. Quando possível, seguiam-se determinados grupos e eventualmente, crianças isoladas. Observamos se algumas situações se repetiam, com intuito de verificar se havia uma rotina $e$ se possuíam um significado particular para as crianças. $^{7}$

$\mathrm{O}$ recreio possibilitou o levantamento de material significativo quanto aos usos do tempo e do espaço $e$ as relações das crianças entre si e com os/as inspetores/as. Havia uma cumplicidade favorável na relação da pesquisadora com as crianças e inspetores/as e um certo espanto de todos pelo estudo se dar no momento do recreio, considerado pouco importante pelos adultos, segundo os pesquisados de todas as idades. As crianças, mais as meninas do que os meninos, integravam a pesquisadora em suas brincadeiras e até vinham em grupos ou individualmente trazer histórias e questões que julgavam importante transmitir. Com a realização de observações em sala de aula, no segundo semestre, em turmas de $3^{\mathrm{a}}$ e $4^{\mathrm{a}}$ séries, houve um maior interesse dos meninos pela pesquisa. Eles passaram a disputar a atenção das pesquisadoras com mais intensidade, contando fatos pessoais e mostrando trabalhos de classe, gerando forte reação nas meninas. Ao fazer a definição da lista de crianças a serem entrevistadas, a expectativa era geral e foi difícil resistir às solicitações de todos e todas que queriam ser entrevistados, o que

7 Coulon, Alain. Etnometodologia e educação. Rio de Janeiro, Vozes, 1995. 
Jogos de gênero

seria impossível no tempo restante de pesquisa, apesar das entrevistas serem realizadas em duplas. ${ }^{8}$

Durante as entrevistas, as crianças contaram muitas histórias $e$, apesar da existência de um roteiro semi-estruturado, cada encontro alimentava e enriquecia as questões para a entrevista seguinte, com outra dupla. Era possível perguntar sobre as ações da criança no recreio e em sala de aula e depois comparar narrativa e ação. A disponibilidade e confiança das crianças em falar sobre si mesmas surpreenderam $e$ proporcionaram um material muito elucidativo para a construção de um diálogo com os registros de campo. Nossa impressão é de que as entrevistas foram, para as crianças, um momento de reflexão sobre o que viviam no pátio. Para nós, foram esclarecedoras das análises que esboçávamos sobre os significados de suas práticas.

Nos registros de campo estão presentes, ainda, as observações sobre as ações das duas inspetoras e do inspetor. As conversas informais com eles ao término do recreio e das aulas, bem como as entrevistas individuais posteriores, complementaram as observações $e$ se deram em um clima de amabilidade $e$ curiosidade, similar à atitude das crianças.

Embora observássemos nos recreios inúmeros conflitos de oposição, que de modo sintético definimos como busca de distanciamento físico e de rompimento, com graus variáveis de agressividade que poderiam culminar em violência, chamounos a atenção o fato de que, na maioria das interações que envolviam meninos versus meninas, predominava uma mescla de agressividade com elementos lúdicos, com intuito de aproximação. Sobre estas formas de interação construímos a hipótese da predominância naquele contexto de uma

\footnotetext{
8 As duplas foram organizadas em função da pertinência ao mesmo sexo e da amizade e confiança mútuas expressas pelas próprias crianças. Outros estudos já indicavam que estes sentimentos comumente se dão entre crianças da mesma idade e sexo o que foi corroborado nas observações desta pesquisa. Ver BERNARDES, Nara. M.G. Crianças oprimidas: autonomia e submissão. Tese de Doutorado em Educação/ Universidade Federal do Rio Grande do Sul, 1989.
} 
sociabilidade do conflito, caracterizada pelo distanciamento entre os sexos nos momentos amistosos e uma aproximação proposital por meio de ações conflituosas, que pareciam, muitas vezes, ser a única forma possível de estar juntos. Essas ações de aproximação conflituosa entre meninos e meninas podem ser caracterizadas em três modalidades: atividades turbulentas (como correrias, pega-pegas e perseguições), episódios de invasão (em que crianças de um sexo invadiam os espaços $e$ as brincadeiras em desenvolvimento por um grupo de outro sexo) e provocações verbais ou físicas, que incluíam os xingamentos proferidos pelos meninos e os tapas das garotas contra eles.

\section{Agressividade e violência: fugindo dos absolutos}

Agressividade e violência permeiam os conflitos entre seres humanos e não seria diferente entre as crianças, o que tem motivado muitos estudos sobre o desenvolvimento infantil. Nesta análise utilizamos o conceito de conflito como manifestação de interesses diferentes e/ou contrários, em que um dos lados procura superar a resistência do outro visando à realização do seu interesse, quer por meio de cooptação e convencimento, quer pela anulação do interesse do outro. Todo conflito implica, portanto, oposição e luta, e vem carregado de agressividade. ${ }^{9}$

$\mathrm{O}$ termo agressividade possui muitos significados. Dentro de uma concepção histórico-cultural podemos considerar a agressividade como concomitante ao desenvolvimento das relações sociais, nas quais indivíduos e grupos exercem ativamente seus interesses e lutam para realizá-los no processo de tornarem-se humanos em uma coletividade que é definidora, em última instância, das fronteiras até onde se pode chegar sem a perda da humanização construída. Sobre esse processo, Strayer

9 Contribuíram para essa definição as concepções de Olivier sobre o significado da "lutinha" entre os meninos, em seu estudo sobre as brigas e os jogos de regras. OLIVIER, Jean. Das brigas aos jogos com regras: enfrentando a indisciplina na escola. Porto Alegre, Artes Médicas, 2000. 
Jogos de gênero

afirma que, entre as crianças, "a emergência das relações sociais estáveis dentro de um grupo impõe limite à expressão do conflito". ${ }^{10}$

O exercício de lidar com a agressividade, que se inicia na infância e nela estabelece sua base ${ }^{11}$, é diferente a cada momento da vida e passa por um permanente processo de aprendizagem $e$ transformação na vivência de diferentes relações sociais. No entanto, assim como não podemos falar da infância em sentido singular, genérico e atemporal ${ }^{12}$, também não podemos falar da agressividade e do conflito nesse sentido, porque há vários fatores que alteram a dinâmica e o conteúdo das interações infantis.

Ao estudar o que leva ao apaziguamento após o conflito entre crianças de uma pré-escola brasileira, Fríoli ${ }^{13}$ afirma que as crianças incluem em sua definição do que é um amigo a possibilidade de brigar, tanto em atividades livres como dirigidas. A autora conclui que os conflitos se apresentam mais freqüentemente entre amigos do que não-amigos e que a diferença nos conflitos entre amigos é que as brigas são menos duras e resolvidas mais rapidamente, o que a leva a argumentar que brincar e exercer a agressividade são elementos constitutivos do fazer infantil.

Pensamos que a agressividade, que se inicia em um processo ativo de manifestação de disputas de interesse, realiza-se sempre em interações sociais perpassadas por relações de poder,

\footnotetext{
${ }^{10}$ StRAYER, 1976 apud Fríoli, Paula Maria de Almeida. Conflito e reconciliação entre crianças pré-escolares. Tese de Doutorado em Psicologia/USP, 1997, pp.4-5.

${ }^{11}$ Wallon, Henry. Psicologia e educação da infância. Lisboa, Estampa, 1975.

${ }^{12}$ SARMENTO, Manuel. As crianças e a infância: definindo conceitos, delimitando o campo; PINTO, Manuel. A infância como construção social. Ambos em SARMEnTO, M. e Pinto, M. (orgs.) As crianças: contextos e identidades. Minho, Universidade do Minho, 1997; AYDT, H. e CORSARO, W. Differences in children's construction of gender across culture: an interpretive approach. American Behavioral Scientist, vol. 46, $\mathrm{n}^{\circ}$ 10, June 2003.

${ }^{13}$ FRÍOLI, P. M. A. Conflito e reconciliação... Op. cit.
} 
camufladas ou manifestas, $e$ as interações infantis não fogem à regra. Embora muitas vezes, na prática, agressividade e violência se confundam, estabelecemos uma distinção entre seus significados: a primeira, ao exceder-se e adquirir finalidade destrutiva, transforma-se na segunda. Partimos da definição de Costa, que afirma ser a violência

\begin{abstract}
um artefato da cultura $e$ não seu artífice. Ela é uma particularidade do viver social, um tipo de "negociação", que através do emprego da força ou da agressividade visa encontrar soluções para conflitos que não se [deixam] resolver pelo diálogo e pela cooperação. ${ }^{14}$
\end{abstract}

A agressividade é utilizada pela violência, mas é diferente dela. Aqui, o autor ressalta uma segunda idéia: as expressões da agressividade humana não são necessariamente violentas. Como nem todo conflito traz em si a idéia de destruição do outro, mesmo que contenha agressividade (física ou não), a ação agressiva nem sempre é sinônimo de violência. É na sutileza de sua transformação qualitativa que o conflito se expressa em negatividade e, em caso extremo, no conflito violento.

Finalmente, Costa também afirma que o ato de traduzir uma ação como violenta ou não passa pelo conjunto de significados para os três sujeitos envolvidos - a vítima, o agente e o observador. Não só a finalidade do agente entra em jogo, mas os significados que os demais envolvidos atribuem ao ato. $\mathrm{O}$ autor destaca que a percepção da vítima $e$ do observador são fundamentais,

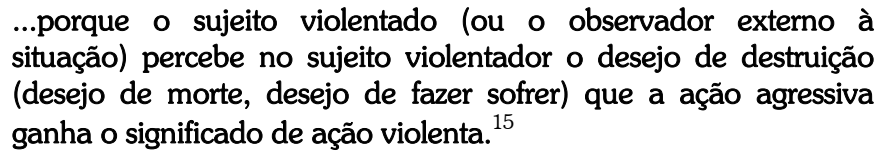

${ }^{14}$ CostA, Jurandir Freire. Violência e Psicanálise. $3^{\mathrm{a}}$ ed., Rio de Janeiro, Graal, 2003, p.62. (grifos do autor)

${ }^{15}$ ID., IB., p.39. (grifos do autor) 
Jogos de gênero

Observemos as cenas a seguir, registradas no diário de campo da pesquisa ${ }^{16}$ :

Como estamos fora do horário escolar, não há inspetores. Converso com o guarda que circula pela escola. No espaço onde jogam futebol no recreio, meninos e meninas estão em uma confusão, discutindo o jogo. O guarda diz, despreocupado, que "são coisas de criança". Não muito distantes de nós estão quatro meninas. Um menino chega e dá um empurrão em uma delas, que retruca. Todas ajudam, ele pára. Conversam rapidamente sem que eu ouça. Chega mais um menino e saem correndo em pegapega, meninas versus meninos. (DC, 20/03/01)

Crianças se agrupam no espaço contíguo à quadra descoberta. A cada momento entram mais meninas diferentes, às vezes arrastando um menino para mostrá-lo a mim, dizendo os nomes com que eles as xingam e de que elas não gostam, ao que eles reagem repetindo o nome $e$ rindo. Formam um grande grupo de cerca de 30 a 40 crianças no espaço entre o rio e a quadra descoberta. As meninas batem nos meninos com relativa força. Eles não expressam sofrimento, mas pela forma como se esquivam dos golpes e tentam segurá-las, parece doer um pouco. (DC, 05/09/2001)

Essas interações entre meninos e meninas por meio de tapas e xingamentos ou provocações seguidas de pega-pega eram comuns na escola pesquisada. Na primeira situação, o empurrão inicial é visto de modo ambígüo em sua agressividade já que a menina retruca. Mas, na seqüência, a provocação age como um chamado à brincadeira que, por sua vez, integra um novo menino que chega. Para o conjunto dos sujeitos envolvidos, até mesmo o guarda, o contexto manifestava uma predominância lúdica.

${ }^{16}$ A partir de agora todos os registros retirados dos Diários de Campo serão especificados como DC. 
Na segunda situação, a ambigüidade está presente não só na força dos tapas dados pelas meninas, como na ação de se esquivarem e nas risadas dos meninos. Cabe aqui uma reflexão sobre o significado da ação agressiva-lúdica para aquele que a recebe. Para Santos, essa percepção do sujeito pode estar ligada à idéia de ultrapassagem de limites presente na noção de "excesso" e de "coerção", ou seja, a violência que se configura como um dispositivo de controle, aberto e contínuo:

Força, coerção e dano em relação ao outro, enquanto atos de excesso, presentes nas relações de poder seja no nível macro, do Estado, seja no nível micro, entre os grupos sociais (...) a violência seria a relação social de excesso de poder que impede o reconhecimento do outro - pessoa, classe, gênero ou raça mediante o uso da força ou da coerção $(. . .)^{17}$

Dessa forma, a alternativa de aproximação por tapas $e$ xingamentos transitava por uma linha tênue entre a agressividade $e$ a violência e nem sempre produzia o resultado desejado, seja pela duplicidade de sentidos (podia aparentar/ter finalidades tanto destrutivas quanto lúdicas), seja pelo intenso sentimento de raiva que provocava nas crianças atingidas. Esse aspecto aparece nas falas dos meninos entrevistados ${ }^{18}$ :

André: A Mônica [personagem das histórias em quadrinhos de Mauricio de Souza] não tem um Sansão? Então, a Sabrina trouxe um Sansão deste tamanho! Eu falei assim: "Oi, Sabrina!" e ela: "Ta,ta,ta!", bateu em mim!

Tânia: As meninas batem muito em vocês?

\footnotetext{
${ }^{17}$ SANTOS, José Vicente Tavares dos. A violência na escola: conflitualidade social e ações civilizatórias. Educação e Pesquisa. vol. 27, n 1, São Paulo, jan/jun. 2001, pp.101-108.

18 Todos os nomes são fictícios.
} 
Jogos de gênero

André: Bate. Lembra que a Sabrina sangrou aqui a minha orelha? Ficou assim! E quando segura a orelha dela, começa a chorar! [...].

TA: Então a Sabrina já bateu no Jorge e no André?

Raul: $E$ já bateu em mim também.

TA: E as outras meninas, também batem?

RA: Algumas, algumas. A Fabiana. A gente gosta de ficar com a Fabiana, com a Larissa, porque elas brincam, batem na gente, mas a gente pode bater nelas.[...] Com a Fabiana, com essas meninas, a gente leva na brincadeira, mas com a Sabrina, a Bruna, a Alessandra, a gente leva ...

[André completa]: Na porrada, mesmo!

RA: Briga de verdade!

TA: Tem meninas que batem pra machucar?

RA: Tem meninas que batem brincando e acabam machucando. ( $4^{\mathrm{a}}$ série, Entrevista nov. 2001)

Pode-se analisar que brincar e bater expressavam significados muito parecidos nas relações de gênero entre as crianças nessa escola. Mas o ato de bater também pode significar violência para todos que o praticam: estão em jogo a intencionalidade presumida por quem apanha $e$ a intensidade da força utilizada. O sentido de violência como interesse destrutivo e a noção de excesso, sempre informados pela percepção dos envolvidos, podem ajudar a entender as histórias relatadas. As relações de gênero, como as demais relações sociais, são permeadas por relações de poder. Por sua vez poder e violência, apesar de serem conceitos distintos, podem se apresentar combinados nas relações sociais. Se o poder, no sentido foucaultiano do termo ${ }^{19}$, está presente em todas as relações sociais, e se esses poderes centralizados ou difusos são negociados permanentemente entre grupos ou indivíduos, o mesmo não se

${ }^{19}$ Foucault, Michel. Vigiar e Punir: história da violência nas prisóes. $1^{\mathrm{a}}$ ed. Petrópolis, Vozes, 1987. 
pode dizer da violência. $\mathrm{O}$ excesso de dano e o excesso de poder são elementos que, articulados pelo desejo de destruição $e$ controle, provocam violência.

Nos conflitos entre meninos e meninas observados, quais momentos expressavam a percepção pela criança violentada de que o controle da situação havia passado às mãos do outro $e$ às suas finalidades destrutivas? Se a definição de ter havido ou não excesso seria, fundamentalmente, da vítima, os observadores (outras crianças, inspetores, inspetoras e pesquisadora) também contribuiriam no ato de traduzir a ação como violenta? A noção do excesso e a percepção dos envolvidos permitem compreender as fronteiras presentes nas situações de conflito. Ainda que tal análise aparente ser demasiadamente relativista, por envolver também a subjetividade do observador e mesmo das pesquisadoras que, em última instância, interpretam os signos corporais e verbais, ela nos parece necessária e adequada para a compreensão do conceito dinâmico de violência que adotamos aqui.

Não que toda violência seja subjetiva, o que seria negar a existência na realidade escolar, por exemplo, de formas de violência às quais não se aplica esta mesma fluidez de significados. Há determinadas ações cujos significados são vistos como violência em quaisquer situações em que se apresentem, tais como intimidações, lesões corporais, roubos, etc. No entanto, ao estudar crianças e adentrar na complexidade e ambigüidade de suas interações cotidianas, foi necessário utilizar um instrumental que permitisse entender a fluidez entre agressividade e violência que caracterizavam a forma de sociabilidade na escola estudada.

As provocações verbais, igualmente, pareciam caminhar nessa mesma ambigüidade de sentidos. Camacho, ao refletir sobre as violências sutis, também a partir de observações feitas em uma escola, afirma que há apelidos carinhosos, que indicam intimidade 
Jogos de gênero

e pejorativos, que o receptor ${ }^{20}$ considera ofensivos. Em geral, os apelidos rejeitados pelos receptores

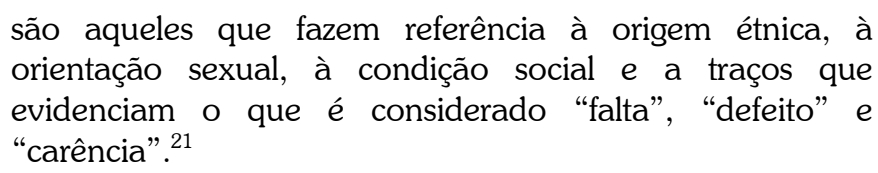

$\mathrm{Na}$ visão dessa autora, o significado para aqueles que recebem o apelido é também chave para definir os níveis de agressividade; a partir da atribuição destes significados, o ato poderá ser considerado ou não violento. Camacho constrói uma reflexão sobre o que chama "ações efetuadas como ante-sala da violência" e que podem levar a ela, uma vez que "as fronteiras entre a sala ou os espaços típicos da violência são tênues e o trânsito dessa passagem nem sempre é percebido" com "os significados se misturando na prática". ${ }^{22}$ Cita como exemplo um aluno que, tendo recebido um apelido (ante-sala da violência), considera-o ofensivo, reagindo com pontapés e socos, e agressor e agredido passam para uma situação violenta.

Nossas observações indicam que a instabilidade emocional provocada pelos tapas dados pelas meninas e os xingamentos utilizados pelos meninos eram mais complexas que os sentimentos provocados por outras interações conflituosas como as invasões de brincadeiras de uns pelos outros ou um leve empurrão para se iniciar um pega-pega. Devem, por isso, ser analisadas com cautela em seu significado de aproximação, visto serem ações rejeitadas por quem os recebia e que tendiam, com relativa facilidade, a provocar rupturas entre os sexos e o reforço de significados de gênero bi-polares e padronizados.

${ }^{20}$ Conceito utilizado por CAMACHO, Luiza Mitiko. As sutilezas das faces da violência nas práticas escolares de adolescentes. Educação e Pesquisa, vol. 27, nº 1, São Paulo, jan/jun. 2001.

${ }^{21}$ Id., ib., p.137.

22 Id., ib. 
$\mathrm{Na}$ verdade, tanto se podiam encontrar ações conflituosas que se desenvolviam expressando forte oposição entre meninos e meninas desde o seu início, quanto ações que eram tentativas, de um dos lados, por uma aproximação. Na segunda situação, o lado que reagia atribuindo um caráter de oposição à provocação inicial, passava a aceitá-la como brincadeira e permitia a mudança do caráter do conflito. O contrário também poderia ocorrer: um excesso de agressividade aplicado à ação levaria, mesmo utilizado dentro de um conflito por aproximação, a uma total oposição $e$ afastamento entre os sexos. O conflito por aproximação continha uma combinação de lúdico e níveis variáveis de agressividade, ressaltada quando o grupo que sofria a provocação não aprovava o tipo de ação utilizada como aproximação e se mantinha resistente, o que transformava a situação em um conflito por oposição:

Durante um jogo de futebol no recreio, três meninas da $4^{\mathrm{a}}$ série estão no gol atrapalhando o goleiro Thomas, que é da sala delas. Thomas vai para o meio do campo e outros dois meninos chegam, riem e dizem a elas: "Isso, fiquem desse lado também". Parece que assim elas ajudavam o time deles. Thomas volta $e$ todas as meninas estão na frente do gol: pulando, uma levantando a outra, uma sacudindo um urso de pelúcia enorme, outras se movimentando em duas filas paralelas para não levarem boladas. Um menino do outro time grita com elas: "Sai, vocês estão atrapalhando, porra!". Um outro pega a bola, visivelmente chateado, vai para o lado oposto da quadra descoberta e começa a bater bola daquele lado. Fui até as meninas conversar e me disseram: "A gente só queria brincar com eles de polícia $e$ ladrão!" Apenas Thomas foi brincar com elas. (DC, 28/08/01)

Para os meninos que não gostaram da brincadeira na cena acima, a situação poderia ter se desenrolado de outro modo, nada amistoso, e avançar para algum tipo de agressividade. Assim, a idéia de ante-sala proposta por Camacho nos pareceu bastante 
Jogos de gênero

proveitosa, embora prefiramos renomeá-la como momento transicional, porque permite perceber melhor a movimentação em ambas as direções, lúdica ou violenta. A expressão ante-sala constitui uma imagem de que a situação tenderá sempre a se converter em violência, o que não é verdadeiro para o caso dos conflitos infantis observados, nos quais era comum o retrocesso ao momento lúdico. No interior desse momento transicional, desenvolviam-se ações com graus variáveis de agressividade, podendo ser consideradas situações de oposição por um dos lados ou mudando de lado no decorrer das ações, numa instabilidade de significados. No extremo de agressividade desse momento, o conflito convertia-se em violência pelo alto grau de danos provocados ao outro, ou em sentido contrário, ao haver uma diminuição máxima da agressividade, o conflito recuava em direção ao momento lúdico de onde eventualmente partira.

\section{Todo jogo é um arriscar-se}

Em muitas situações conflituosas era possível acompanhar essa movimentação do momento lúdico para o transicional e viceversa. Para construir a noção de momentos diferenciados dentro de uma situação de conflito e explicitar a existência do momento lúdico, foi necessário aprofundar o significado do conceito de "lúdico" e compreender sua utilização pelas crianças. A cultura lúdica, de acordo com Brougère, é resultado de um movimento interno e externo de construção da criança durante a própria atividade lúdica. Nessa interação social, a criança reelabora cada experiência nova em função das experiências anteriores, das competências que tem a cada momento e da realidade externa ao jogo:

Toda a interação supõe efetivamente uma interpretação das significações dadas aos objetos dessa interação (indivíduos, ações, objetos materiais) e a criança agirá em função dos outros elementos da interação, para reagir também $e$ produzir assim novas significações que vão ser interpretadas 
Tânia Cruz e Marília Carvalho

pelos outros [...] A cultura lúdica não está isolada da cultura geral. Essa influência é multiforme e começa com o ambiente, as condições materiais. As proibições dos pais, dos mestres, o espaço colocado à disposição na escola, na cidade, em casa, vão pesar sobre a experiência lúdica. ${ }^{23}$

O autor frisa que há uma cultura lúdica dos adultos e que esta só compõe a cultura lúdica infantil em parte, porque dois aspectos estão presentes na complexidade de produção de significações pelas crianças: ora condicionamentos, ora criatividade. A cultura lúdica infantil, apesar da multiplicidade simbólica que lhe é intrínseca em diferentes sociedades, tem uma especificidade que compreende o uso de "um certo número de referências que permitem interpretar como jogo atividades que poderiam não ser vistas como tais por outras pessoas". ${ }^{24}$ Essa situação pode ser constatada na dificuldade de um olhar externo $e$ não infantil, distante dos códigos comuns daquela atividade, na distinção entre o que é uma briga de brincadeira e uma briga de verdade.

Em campo foi possível presenciar muitas situações ambíguas:

Fernando, da $2^{\mathrm{a}}$ série, tira o chiclete da boca e ameaça grudá-lo nas meninas. Cecília, da mesma turma dele, que fazia um arranjo com flores do latão de lixo [...] pede que pare [...] Fernando percebe que ela achou que ele podia, de fato, grudar o chiclete nelas e diz: "Não, imagina! Eu não vou colocar em você de jeito nenhum! É brincadeira!" Mas aí o jogo se inverte e Cecília o desafia: "Ah, é? Não vai, não?" Ao olhar de enfrentamento de Cecilia, ele muda a fisionomia e parece, então, decidido a colocar o chiclete nela, que ao perceber isso reclama, fica brava. Ele segura forte no braço dela. Ela ameaça gritar. Ele diz: "Sua

${ }^{23}$ BrougÈRE, Gilles. A criança e a cultura lúdica. In: KISHIMOTO, Tizuko Morchida. (org.) O brincar e suas teorias. São Paulo, Pioneira, 1998, pp.27-28.

${ }^{24}$ ID., IB., p.24. 
Jogos de gênero

bobona!" Outra menina passa veloz por Fernando, bate a mão nele e diz: "Amigão!", e ele corre atrás dela em pegapega, fazendo cara de monstro. Toca o sinal do recreio e todos correm para as filas. (DC, 03/09/2001)

Três meninas pequenas estão a curta distância de um menino. Quando ele ameaça se mexer, elas correm, não deixando que ele as pegue e daí voltam para o mesmo lugar. Quando me vêem se aproximam de mim e pergunto se estão brincando de pega-pega. Uma delas responde: "Não estamos brincando, não... e não é pega-pega". Despede-se correndo. Elas continuam a ação e o menino corre atrás delas, meio desanimado. Ele quer ficar perto delas, pede para elas pararem de correr, mas não adianta. (DC, 12/03/2001)

$\mathrm{Na}$ primeira cena, o garoto que promovia um conflito por aproximação, acaba sem querer se vendo em uma oposição $e$ sendo "salvo" por outra menina que passou por ele brincando e o tirou da cena em que a menina talvez se dispusesse a enfrentá-lo de modo sério, o que ele não queria. Na segunda cena, o menino queria se aproximar amistosamente, enquanto as meninas reagiam de modo conflituoso, fazendo um jogo de que não o queriam $e$, na verdade, brincavam com ele à sua revelia, que desejava brincar de outro modo $e$, por isso, ficou triste. A nuance da resposta delas de que não estavam brincando $e$, ao mesmo tempo, as características teatrais do jogo de gênero que adotaram, sugerem que elas tinham noção de que, para o garoto, aquilo não era bom, mas elas insistiam mesmo assim.

Os elementos de jogo, observados em muitas situações desencadeadoras de conflitos, permitem inferir que a oposição entre meninos e meninas poderia ser, na verdade, um jogo de aproximação. $\mathrm{O}$ ato de chegar perto de alguém e puxar-lhe o boné, aguardando a reação, era produzido voluntariamente, em um contexto no qual muitas eram as alternativas de diversão. A disputa de objetos pessoais e o clima assim criado eram fonte de prazer, mesmo por parte da criança que sofria a provocação, 
como demonstravam suas risadas e sua persistência na atividade, ainda quando havia também expressões de desprazer. Apesar de, em geral, as crianças obedecerem a regras implícitas nesses jogos, a incerteza do resultado das ações - como "o que provoca foge" $e$ "o que é provocado corre atrás" - produzia um clima de disputa permanente nos jogos:

Estou sentada nas cadeiras velhas do pátio, ao lado de Diego, da $2^{\mathrm{a}}$ série. De repente uma menininha que ia passando o vê, faz cara de surpresa e grita: "Ahhh!" e parte pra cima dele, que sai correndo. Outras duas vêm e ficam perto de mim. Surpresa, eu pergunto o que tinha havido $e$ uma delas me diz: "É que ele fica pisando no nosso pé e agora a gente vai pegar ele!" (DC, 24/04/01)

A ação imaginativa esteve presente: se o provocado não fingisse acreditar que a provocação era séria não haveria o jogo não-sério. Mas em todas as situações lúdicas havia uma margem para que o jogo cedesse lugar ao conflito violento ou ao abandono da situação e, em ambos os casos, a tentativa de aproximação fracassaria.

O risco do jogo está exatamente na diferente gama de sentidos que ele provoca em cada um de seus participantes, o que leva à instabilidade do jogar. Para Kishimoto ${ }^{25}$, a cultura lúdica infantil expressa essa oscilação de significados, de acordo com intenções e sentimentos, no instante em que a criança brinca, porque às vezes a criança "brincando" diz: "agora não estou brincando", mas logo em seguida, entra na brincadeira. O que diferencia o primeiro momento (não brincar) do segundo (brincar) é a intenção da criança, o que mostra a grande dificuldade de realizar pesquisas empíricas sobre o jogo infantil.

Assim, quando as crianças brincam, elas apresentam tanto jogos com regras bem precisas quanto esquemas de brincadeiras

${ }^{25}$ Kishimoto, T. M. O jogo e a educação infantil. Perspectiva, $\mathrm{n}^{\circ} 22$, Florianópolis, $2^{\circ}$ sem. 1994, p.114. 
Jogos de gênero

diferentes com estruturas gerais e imprecisas que permitem organizar jogos de imitação ou ficção, esquemas bem gerais utilizáveis em jogos muito diferentes. Nesse sentido, a criança joga quando

dispõe de significações, de esquemas em estruturas que ela constrói no contexto das interações sociais que lhe dão acesso a elas. Assim, ela co-produz sua cultura lúdica, diversificada conforme os indivíduos, o sexo, a idade, o meio social. ${ }^{26}$

Os conflitos lúdicos entre meninos e meninas observados naquela escola eram freqüentemente bem sucedidos em seus objetivos, apesar dos riscos:

Em um dos cantos do pátio, um grupo de crianças muito pequenas chegam emboladas. Parecem ser do primeiro ou segundo ano. Ao me aproximar, percebo que é um pegapega de meninas contra meninos: eles derrubam a menina e começam a chutá-la. Ela continua rindo muito, mas a inspetora Layde se aproxima e todos se dispersam. (DC, $23 / 10 / 01)$

À primeira vista, a perseguição de um grupo de meninas contra um grupo de meninos poderia parecer nada mais que uma guerra entre os sexos, mas também eram perceptíveis elementos lúdicos, presentes nas risadas, na pouca força dos chutes e no fato das crianças não solicitarem qualquer intervenção externa, mesmo que esta tenha ocorrido. Para Brougère ${ }^{27}$, a vivência do jogo contempla um aspecto estrutural, porque todos os elementos utilizados nele fazem com que a criança viva experiências do processo cultural e da interação simbólica da cultura humana: agir de modo interativo; aprender progressivamente; conhecer $e$

${ }^{26}$ Brougère, G. A criança e a cultura lúdica. Op. cit., p.28.

${ }^{27}$ ID., IB. 
acessar elementos heterogêneos e com diversidade cultural; interpretar, significar e criar individualmente e em grupo. No entanto, delinear as etapas ou as aprendizagens de cada jogo não deve esconder a principal característica do jogo infantil, que é a relação da criança com a realidade que a rodeia. As brincadeiras, dentre elas o jogo, não são atividades para, mas atividades nas quais podem aparecer os elementos citados. O jogo, apesar do seu caráter não-sério, é a principal forma que a criança utiliza para se estabelecer no mundo e expressar-se, o que, de certo modo, torna-o sério para ela.

\section{Jogos de gênero: sujeitos e significados}

O mesmo pode-se dizer especificamente da construção das relações de gênero. Barry Thorne utilizou a metáfora do jogo para analisar as interações infantis nos pátios de recreio, refeitórios e corredores de escolas elementares norte-americanas. Ao se referir às interações tranqüilas ou conflituosas entre meninos $e$ meninas Thorne $e^{28}$ explorou alguns dos múltiplos significados do verbo to play em inglês, agrupando-os em quatro categorias: ação, atividade engajada, na qual os gêneros são produzidos ativamente, em práticas sociais que ora reforçam o senso dicotômico de gênero em brincadeiras de meninos contra meninas, ora solapam este sentido em projetos de cooperação; performance dramática, no gosto pelos rituais, no teatro cotidiano com regras seqüenciais explícitas, aplicadas em ações que seguem sempre o mesmo script em cenas que podem envolver xingamentos sexualizados, frases prontas como reação à entrada de um menino em um grupo de meninas, ou atos de agressão entre meninos e meninas, situações que as crianças sempre dão a entender "serem apenas brincadeiras"; jogo como liberdade de ação, em que os significados de gênero não só são instáveis, como

${ }^{28}$ THORNE, Barrie. Gender Play: girls and boys in school. New Jersey, Rutgers University Press, 1997, pp.4-6. 
Jogos de gênero

podem não ocupar o primeiro plano em determinado momento, pela fluidez que a noção de jogo permite aos jogadores; jogo como seriedade e relações de poder, características em geral, em outros estudos, presentes apenas quando se fala do mundo adulto, mas que Thorne percebe em manifestações de tristeza e raiva nos jogos e nas ações de disputa, com implicações para as relações de poder entre crianças e para a construção dos termos de gênero.

Este conceito de jogos de gênero (conflituosos ou não) contribui para a análise das cenas de conflitos entre meninos $e$ meninas que observamos:

O recreio está acabando. Vejo a inspetora Rosa conversando séria, visivelmente transtornada, com oito meninas da $4^{\mathrm{a}}$ série, e o inspetor Paulo do lado. [...] Logo as meninas saem, porque o sinal já havia tocado há algum tempo. Comento: "E aí, Rosa, foi um dia incrível!", e ela: "Meu deus, mais um dia como esse e eu morro! Amanhã elas não vão ter recreio! Assim aprendem!". Rosa continua: "[as meninas] estavam no banheiro jogando água nos meninos. Disseram que fizeram isso porque primeiro eles jogaram lixo nelas, $e$ aí elas correram para o banheiro para se lavar e eles foram atrás..." Pergunto quem a chamou $e$ ela responde: "Foi a mulher da limpeza, [ela disse] que estava havendo uma confusão no banheiro. Mas elas [as meninas] não iam chamar nunca, estavam se divertindo muito!" (DC, 05/09/01)

O caráter de diversão observado pela inspetora, apesar do chamado da responsável pela limpeza, denota o clima lúdico que envolvia a provocação recíproca. A utilização do conflito como aproximação podia se dar também por meio de invasões de atividades de um sexo pelo outro:

No gol estão oito meninas, algumas bem pequenas. Tentam tirar da quadra três meninos que participavam do futebol.

Falam com eles. Não adianta. Puxam os colegas escolhidos. Atrapalham o jogo coletivo. Depois de muita insistência, 
Tânia Cruz e Marília Carvalho

conseguem tirar os três. Mas o futebol continua sem eles.

(DC, 06/09/01)

Ao querer atrair os meninos para atividades com elas em jogos de pega-pega, as meninas, por vezes, atrapalhavam o gol, como vimos acima, pegavam objetos pessoais dos jogadores ou batiam neles. Muitas eram as reações a estas invasões. A revolta era uma possibilidade, quando os garotos não aceitavam a tentativa de aproximação das meninas, por verem tal ação como de um grupo aparentemente contrário a eles, o que os levava a expressar um sentimento de oposição e rejeição, refletido até mesmo na busca por apoio de adultos, cobrando do/a inspetor/a de alunos/as a expulsão delas do campo. Os meninos poderiam, também, mesmo relativamente bravos, sair em pega-pega com elas em um jogo conflituoso. Nesse caso, o resultado decorrente do conflito por aproximação negaria, ainda que parcialmente, a existência de barreiras de gênero rígidas na utilização do espaço, com a separação sexual de meninos-jogando-futebol e meninassentadas-conversando, como descrevem inúmeros estudos realizados no Brasil e em outros países. ${ }^{29}$

Para Barry Thorne, os conflitos nos jogos de gênero, mesmo imbuídos de seu caráter lúdico, provocam com intensidade o antagonismo entre os gêneros. ${ }^{30}$ Thorne utiliza a expressão "antagonismos de gênero" para referir-se tanto a oposições entre os sexos (meninos versus meninas), quanto a antagonismos nos sentidos de gênero (masculinidades e feminilidades).

Entretanto é necessário estabelecer uma diferenciação entre sexo, relações de gênero e gêneros, em uma conceituação mais precisa. Há sujeitos e há significados e por isso utilizamos como

${ }^{29}$ BeRnARDES, N. M.G. Crianças oprimidas... Op. cit.; ZaïdmAn, Claude. A administração escolar do regime misto na escola primária. Estudos Feministas, número especial, Rio de Janeiro, out. 1994; AltMAN, Helena. Rompendo fronteiras de gênero: Marias (e) homens na Educação Física. Dissertação de Mestrado em Educação/ UFMG, 1998.

30 ThORNe, B. Gender Play... Op. cit. 
Jogos de gênero

categorias teóricas tanto os gêneros quanto as relações de gênero. Consideramos gêneros como constructos simbólicos de feminilidades e masculinidades em suas combinações variadas, vistos em relação ou separadamente, e relações de gênero como relações sociais entre homens e mulheres, mediadas pelos significados de gênero. Não deixamos de lado a categoria sexo porque a utilizamos para nos referir descritivamente aos sujeitos em sua identidade sexual de homens ou mulheres, de meninos ou meninas. Ao falar, por exemplo, em aproximações entre meninos e meninas em uma brincadeira mista, pensamos em aproximação entre os sexos. Os conteúdos desta aproximação, por sua vez, podem ter conseqüências para as relações de gênero ou para os gêneros masculinos e femininos disponíveis socialmente. ${ }^{31}$

Esses deslocamentos permitem ver como os gêneros podem estar imbricados nas relações entre homens e mulheres (numa movimentação de significados) e, ao mesmo tempo, estar separados deles, atuando como conjunto de significados que norteiam e instauram práticas de instituições, políticas públicas, etc. Enfim, relações de gênero implicam em relações entre homens $e$ mulheres mediadas pelos gêneros, mas os gêneros, como conjunto de significados, têm também uma existência simbólica que ultrapassa os sujeitos. Por isso optamos por trabalhar com a idéia de conflito por aproximação para os jogos de gênero, que envolviam conflito e elementos lúdicos, desencadeados por um dos sexos sobre o outro, quando tinham como objetivo a aproximação entre eles - conforme apreendemos por meio de pistas dadas pelos próprios sujeitos. Isto é, os conflitos

\footnotetext{
${ }^{31}$ Apesar da diversidade de diálogo constituída nestas formulações, elas estão ancoradas com mais intensidade nas concepções de Nicholson e Connel. Nicholson, Linda. Interpretando o gênero. Estudos Feministas, vol. 8, n⿳0 2, Florianópolis, 2000; ConNell, R. W. Políticas da masculinidade. Educação \& Realidade, vol. 20, n 2, Porto Alegre, jul./dez. 1995 e La organización social de la masculinidad. In: OlAVARRIA, José; VALDÉs, Teresa. (eds.) Masculinidad/es: Poder y Crisis. Santiago de Chile, Isis Internacional, Ediciones de las mujeres, $\mathrm{n}^{\circ}$ 24, jun. 1997.
} 
Tânia Cruz e Marília Carvalho

que observamos entre meninos e meninas, muitas vezes, eram utilizados para aproximação entre os sexos, ainda que isso significasse, em alguns momentos, a manutenção de antagonismos nos significados de gênero e, em outros, a suspensão ou atenuação desses antagonismos.

Em outras palavras, mesmo brincando juntas, em alguns casos, as crianças fundamentavam-se em concepções de gêneros masculinos $e$ femininos como elementos divisores $e$ diferenciadores entre o grupo de meninas e o grupo de meninos e, nesses casos, reforçavam os antagonismos de gênero.

Ao reagirem agressivamente à tentativa de aproximação, por exemplo, as crianças poderiam recorrer a elementos generificados, expressos em afirmações como "as meninas não sabem jogar futebol", "os meninos não sabem brincar de casinha", "elas falam de jeito muito delicado" ou "eles só falam 'palavrões' e malícias", que justificavam sua resistência. Compartilhamos com Abecassis ${ }^{32}$ a idéia de que as antipatias mútuas entre meninos e meninas são construídas sobre uma base normativa fundada em diferenças de gênero, nada semelhantes às aversões intra-sexos baseadas em outros critérios.

Em outras situações, entretanto, a aproximação pelo conflito poderia, ainda que em menor grau, relativizar os antagonismos de gênero, ao quebrar fronteiras e permitir às meninas exercerem com maior freqüência jogos como o pega-pega, brincadeiras de movimento e toque corporal com riscos de cair e se machucar, habilidades vivenciadas mais freqüentemente nos jogos praticados pelos meninos, tais como a lutinha e o futebol. Da mesma forma, esse emaranhado de possibilidades e limitações era também vivenciado pelos meninos, quando exerciam suas formas de invasão e brincavam com as meninas em algo tido como feminino. Além de poderem brincar com as meninas, como nas

${ }^{32}$ ABECASSIS, Maurissa et alii. Mutual antiphaties and their significance in middle childhood and adolescence. Child Development, vol. 73, n 5, september/october 2002. 
Jogos de gênero

demais ações conflituosas, nas invasões de atividades das garotas, eles podiam brincar de jogos considerados femininos, como era o caso da "Mamãe Polenta"

Dois meninos chegam e se aproximam da brincadeira das meninas. Depois de olhar um tempo, sem permissão, pulam por entre o grupo de garotas. Elas reclamam, uma xinga, mas, meio a contragosto, aceitam a presença deles. A brincadeira é Mamãe Polenta. A cada pergunta da Mamãe Polenta - "Cadê a polenta que estava aqui?" - os garotos respondem ao mesmo tempo, em grande gritaria. A dupla leva bronca duas vezes por falarem algo que não corresponde à brincadeira, $e$ as meninas jogam a bolsa, dão safanões. Em alguns momentos eles jogam sérios, respeitando as regras. Entram mais meninas. (DC, 02/03/2001)

No entanto, devido às pressões dos colegas, o desejo de entrar, por exemplo, na brincadeira de "Mamãe Polenta" deveria vir necessariamente expresso em ambigüidade, em ações camufladas, que permitissem alternativas de "saída honrosa" sob a pecha de "provocadores", em um contexto no qual os atributos femininos de determinadas ações eram altamente reforçados por uma parcela dos meninos que poderiam designar o garoto transgressor como menininha, mulherzinha ou viado.

\section{Considerações finais}

Escrevendo sobre a co-educação na escola primária francesa contemporânea, Claude Zaidman cita as palavras de um diretor de escola: "O regime misto é como o molho vinagrete: se

33 "Mamãe polenta" é uma brincadeira que envolve encenação seguida de pegapega. A "mamãe" faz a polenta, tranca o forno e vai à missa rezar. Enquanto ela reza, as crianças roubam a chave e comem a polenta. O pega-pega acontece quando a mamãe retorna da missa, pergunta sobre a chave e a polenta até todos saírem em correria. Quem for pego será a nova "mamãe polenta". 
parar de misturar, se separa!". ${ }^{34}$ Efetivamente, essa idéia de oposição, separação e diferenciação de meninos e meninas ainda predomina entre os profissionais da educação também no Brasil, assim como em diversos estudos acadêmicos, embora comecem a pontuar trabalhos que buscam construir uma percepção mais nuançada. ${ }^{35}$

Nosso estudo procurou mostrar a grande variabilidade dos tipos de interação entre os sexos num pátio de recreio, lançando mão, em primeiro lugar, de um conceito de conflito capaz de incluir tanto seus significados de agressividade quanto seus sentidos lúdicos, de forma ambígua e dinâmica. Em segundo lugar, buscamos destacar que, brincando (e brigando) juntos, meninos e meninas estabeleciam jogos de gênero, nos quais tanto se podiam reforçar as bi-polaridades entre os significados antagônicos de feminilidade e masculinidade quanto, ao contrário, diluir-lhes as fronteiras. No que se refere à compreensão dos conflitos, assim como das relações de gênero, procuramos evitar uma mera transposição de seus significados no mundo adulto para as relações entre crianças e construir uma interpretação que desse conta das especificidades do estudo da infância.

Assim, elaboramos a idéia de conflitos por aproximação. Acompanhar a trajetória desses conflitos significava captar o movimento das crianças. Observar a reação de uma criança a uma iniciativa de conflito por parte de outra levava a seu contexto anterior, em nova pista de outra iniciativa, ora provocadora, ora reativa e que, por sua vez, nos trazia perguntas. Como se dava a agressividade ou a violência nessas interações? $O$ que predominava era o caráter lúdico ou a agressividade? Em que

${ }^{34}$ ZAïDMAN, Claude. A administração escolar... Op. cit., p.354.

${ }^{35}$ Por exemplo, Altman, H. Rompendo fronteiras de gênero... Op. cit.; EPSTEIN, Debbie et alli. Boys and girls come out to play: making masculinities and femininities in school playgrounds. Men and Masculinities, vol. 4, no 2, oct. 2001; RENOLD, Emma. "Other" boys: negotiating non-hegemonic masculinities in the primary school. Gender and Education, vol. 16, n 2, jun. 2004; THORNE, B. Gender Play... Op. cit. 
Jogos de gênero

situações os jogos de gênero conflituosos eram adotados e quais as conseqüencias para as relações de gênero? A idéia básica do conflito como mecanismo de aproximação foi construída no decorrer da pesquisa $e$ da análise dos significados expressos nas diferentes situações. Não negamos que os conflitos também podiam ser a manifestação do desejo de distanciamento $e$ oposição entre os sexos, mas, em muitos momentos, era explícita a ação de um lado tentando se aproximar do outro lado, que sentia prazer em fazer de conta que estava sendo incomodado, pois esse era o papel que lhe competia na brincadeira.

A prática de aproximação baseada em relações conflituosas provinha de uma necessidade de as crianças re-equacionarem as relações de gênero no interior daquela cultura escolar. A aproximação parecia ser possível principalmente por meio do conflito ou dissimulada como conflito, devido ao pressuposto de uma oposição entre os sexos e à bi-polaridade entre os significados de gênero, tão marcantes em nossa sociedade. Azeite $e$ vinagre, às vezes, queriam misturar-se, brincar juntos, fazer coisas que pareciam adequadas apenas para o outro, mas essas possibilidades deviam ser ativamente construídas e vinham carregadas de problemas, ambigüidades e desafios.

Evidentemente, muitas questões demandariam novas pesquisas. Há ainda grandes lacunas sobre a compreensão do modo como as crianças, vistas aqui como uma categoria social, têm participado na construção das relações de gênero no período contemporâneo. A infância não é pura imitação, espelho rudimentar de um mundo adulto que a permeia e, menos ainda, a argila sem forma, na qual adultos imprimem suas marcas permanentes. Mas as aprendizagens de gênero constituídas na infância desdobram-se em processos posteriores de reelaboração, os quais sempre dialogam com as lembranças desse período. ${ }^{36} \mathrm{~A}$ depender do contexto, o sujeito pode até mesmo retomar $e$

${ }^{36}$ Trabalhamos com a noção de memória também como construção, processo mutável. 
expressar elementos contra os quais se insurgiu em períodos anteriores, visto ser o processo de consciência e construção de identidades mutável e não linear. ${ }^{37}$

Enfim, as crianças lidam com modos de viver as relações de gênero que lhes são dados a priori e os recriam de maneira particular, em parte reproduzindo, em parte transformando, vivenciando à sua maneira esse movimento de manter e recriar, que é do conjunto da sociedade. Como parte da sociedade, a escola se constitui num contexto múltiplo e contraditório para as ações individuais, mas nela parecem predominar significados de gênero associados à bi-polaridade, ao antagonismo $e$ à hierarquização. Pode a escola apenas "re-agir" às ações infantis? Ou deveria ir além, pensando a si mesma como responsável por políticas de gênero que rompam determinadas amarras? E mais ainda, podem as pesquisas sobre escola, gênero $e$ infância subsidiar educadores e educadoras com elementos para propor ações inovadoras, que incluam suporte e incentivo às práticas transformadoras das crianças - práticas já existentes, embora nem sempre percebidas?

${ }^{37}$ IASI, Mauro. O dilema de Hamlet. O ser e o não ser da consciência. São Paulo, Viramundo, 2002. 